\title{
COLOR DOPPLER ULTRASONOGRAPHY DIAGNOSTICS OF MAJOR BLOOD VESSLES OF THE NECK IN PATIENTS AFTER A STROKE
}

Radulović Snežana ${ }^{1}$, Josović LJiljana ${ }^{1}$, Jokić Aleksandar ${ }^{1}$

${ }^{1}$ Specialized Rehabilitation Hospital Banja Koviljača, Banja Koviljača, Serbia

Introduction: Stroke is a sudden and an abruptly formed loss of brain functions due to the cutting off of the blood flow to the brain caused by occlusion or hemorrhage of the carotid and vertebrobasilar system of arteries and the border zones.

It is classified into two groups: ischemic and hemorrhagic. Most common pathological process in the arterial network of the brain is arteriosclerosis. Color Doppler ultrasonography (CDS) diagnostics is non-invasive diagnostic procedure for the examination of blood vessels which is used to show the interior of the blood vessel wall, estimate the degree of constriction or expansion of the blood vessel, and detect changes in the structure as well as the shape and the length of the blood vessel.
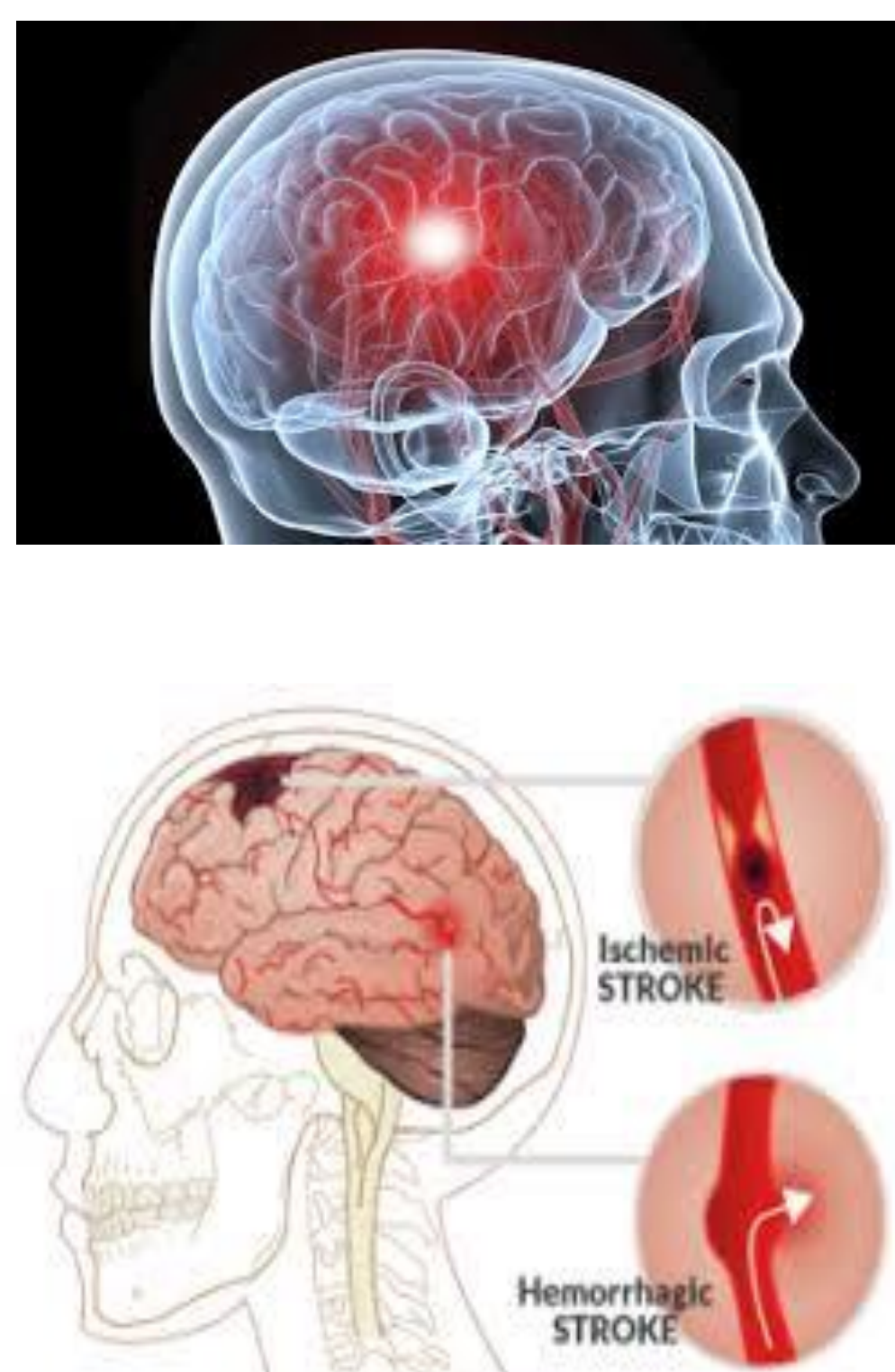

BRAIN STROKE
Purpose: The aim of this paper is to visualize the changes on the major blood vessels of the neck (carotid and vertebral arteries) in patients after a stroke, and to make a correlation between ultrasonography findings in patients after ischemic and after hemorrhagic stroke.

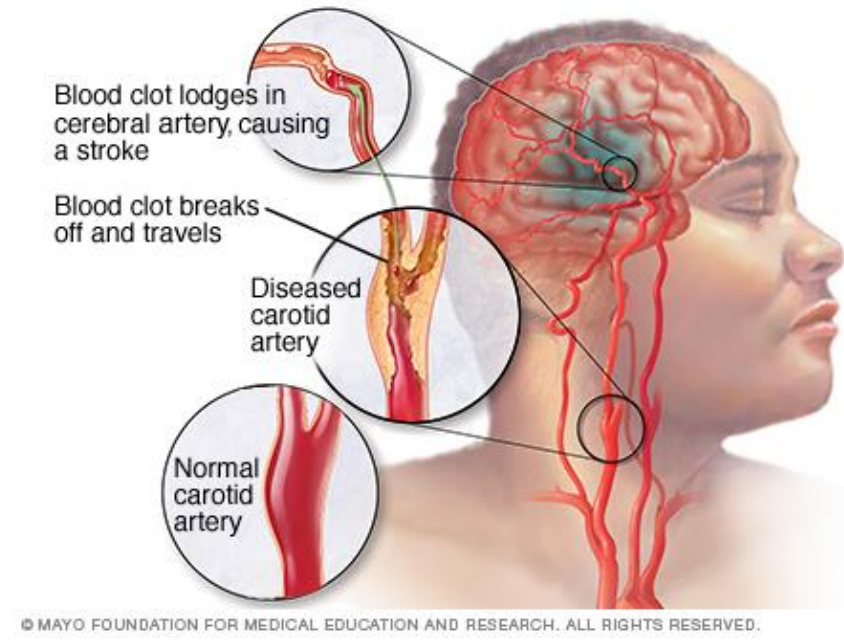

Method: This prospective study performed form January $1^{\text {st }} 2013$ till January $1^{\text {st }} 2016$ encompasses 80 patients who went on a rehabilitation after a stroke, patients of both genders, divided into two groups (of 40 patients) depending on the stroke type ischemic or hemorrhagic. The patients had endocranial CT, and all had CDS of carotid and vertebral arteries. For statistical data processing, it was used $\mathrm{Hi}$ square and T test.
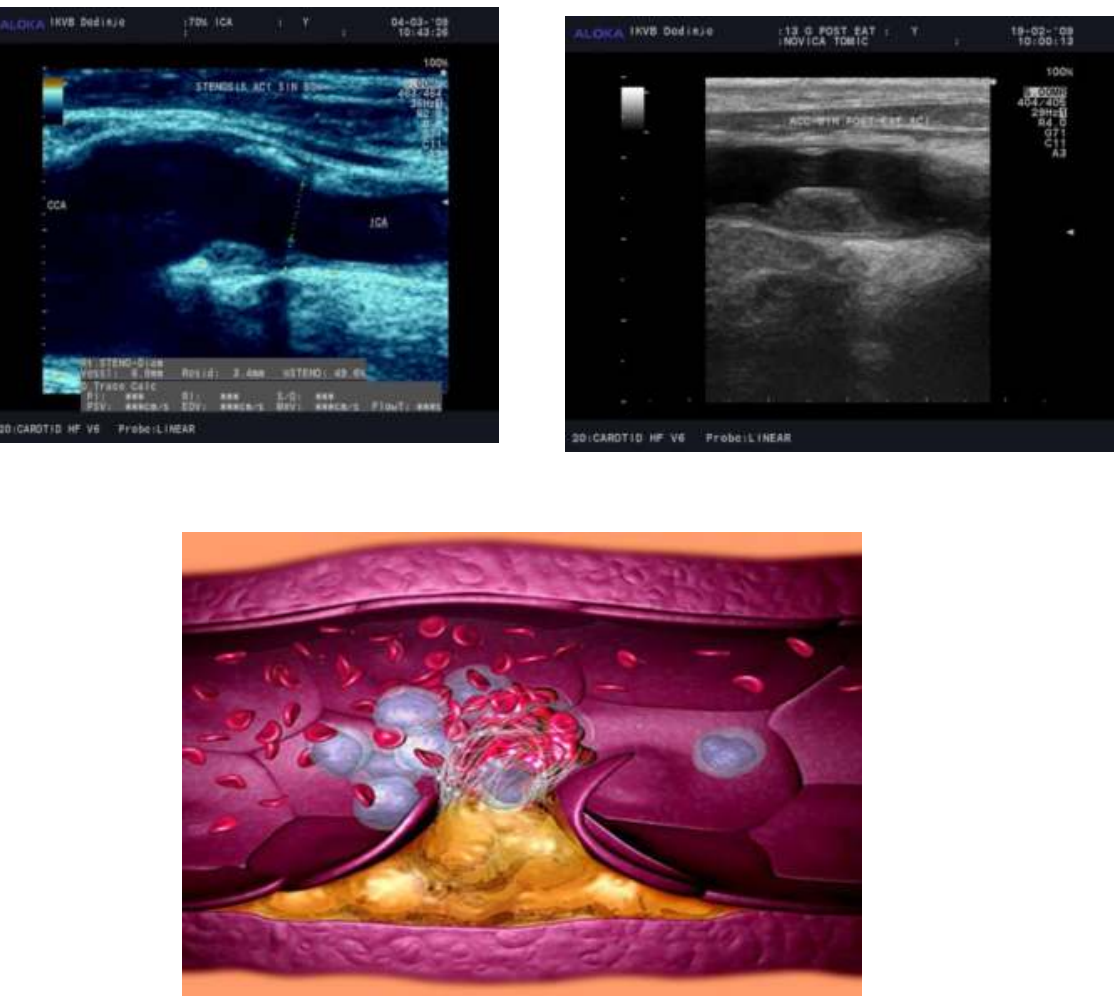

Results:

Statistical data processing shows us that the average age of patients after an ischemic stroke is 70.90 years and after hemorraghic 60.65. By comparing these two groups it is discovered that there is a statistically significant age difference. Hemorraghic stroke affects younger population of patients

Results show that in the ischemic stroke group $87.5 \%$ of the patients has arteriosclerotic changes on the carotid and $50 \%$ on the vertebral arteries, while in the hemorrhagic stroke group, pathological findings are present on carotid arteries in $36 \%$ of patients and in $23 \%$ on the vertebral. By comparative analysis, we have discovered that there are statistically significantly more patients with pathological findings on the carotid and vertebral arteries in the ischemic stroke group. By analyzing arteriosclerosis risk factors, it is determined that all patients had hypertension as a risk factor. By comparative analysis, it has determined that there is statistically significant larger number of patients with risk factors such as hypercholesterolemia and diabetes mellitus in the ischemic stroke group.
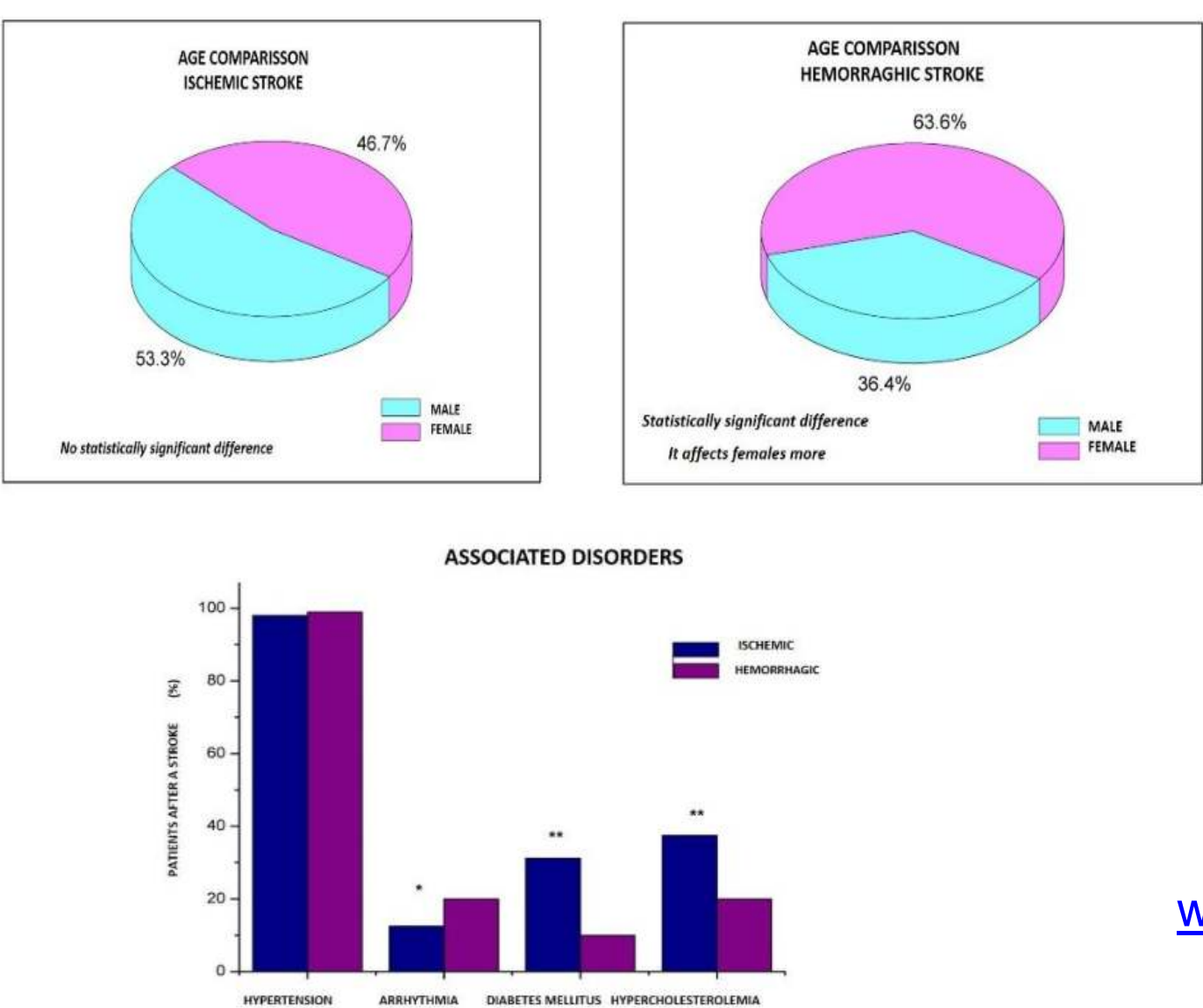
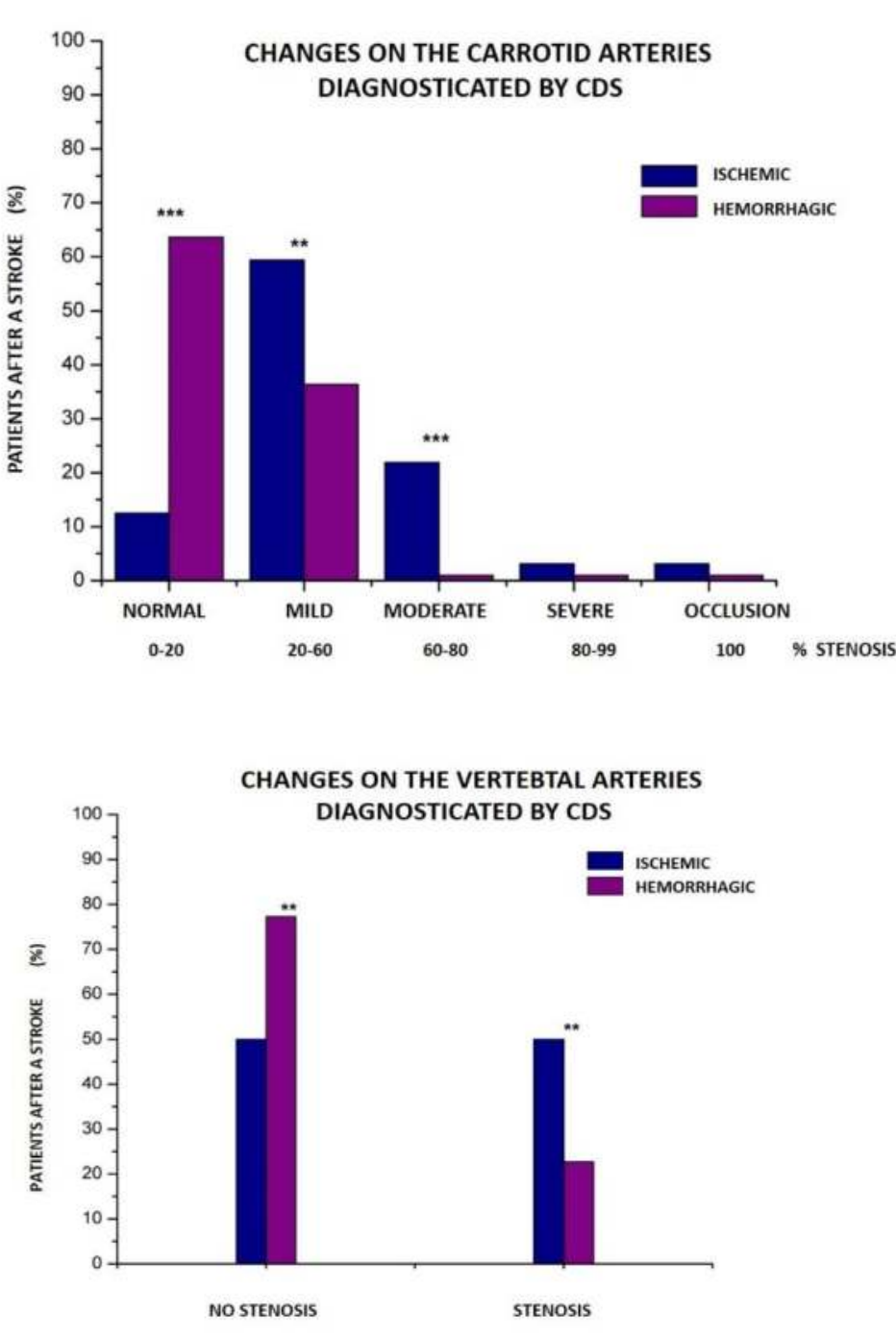

Discussion and Conclusion

Arteriosclerotic changes that lead to significant constrictions of the blood vessels of the neck affect more patients who suffered from an ischemic stroke. Arteriosclerotic changes can be easily visualized by non-invasive diagnostic procedures. By timely execution of noninvasive diagnostic procedures (color doppler ultrasonography) in patients with high stroke risk factors (hypertension, hypercholesterolemia, diabetes mellitus and smoking) the changes on the blood vessels of the neck can be timely detected, proper treatment can be commenced and thus later complications can be prevented. It is necessary to influence significant reduction of the known stroke risk factors 